Retruque

\title{
SOBRE CRÍTICA INTERNA \\ E SABOTAXE LINGÜÍSTICA
}

Gabriel Rei-Doval

University of Wisconsin-Milwaukee 

A primeira e fundamental reacción que me produce o traballo de Anxo M. Lorenzo é de grande acordo na práctica totalidade das avaliacións que realiza. Resulta difícil non concordar cos seus finos diagnósticos e atinadas interpretacións da realidade social do galego. Quizais por iso, e porque a formación e profesión comúns nos fan compartir ferramentas teóricas, instrumentos analíticos, conclusións macrosociolingüísticas e análises sobre a planificación como as referidas, quixera abrir o campo da interpretación ofrecendo algunhas olladas alternativas - parciais e provisionais, sen dúbida- para retomar e deitar luz sobre algúns dos achados xa salientados desde unha perspectiva diferente, complementaria e nunca substitutiva da que el realizou.

Para comezar, quixera eu tamén volver ao título provisorio que en forma de pregunta Anxo Lorenzo recibiu na encomenda deste relatorio: «cabe -aíndaunha interpretación orixinal da situación sociolingüística de Galicia? A propia formulación paréceme xa reveladora da dúbida e de posibles respostas.

En efecto, o adverbio «aínda» incluído na pregunta é relevante en xuño de 2008 -e mesmo un ano máis tarde, mentres reescribo minimamente estas liñas-, tras corenta anos de andaina da Sociolingüística galega. Se formulásemos esta pregunta a comezos dos anos noventa, seguramente todos ou a meirande parte dos que estamos aquí responderiamos afirmativamente: si, é posible unha interpretación orixinal. Pero, aparecido o primeiro Mapa Sociolingüístico de Galicia dos noventa -xunto a diversos e substanciais traballos cuantitativos e cualitativos xurdidos nas dúas últimas décadas- é lexítima e procedente a formulación e preguntarnos se temos aínda marxe para interpretar de xeito orixinal a correlación de linguas en Galicia. A miña opinión é que a descrición de datos macrosociolingüísticos empíricos non permite xa moita marxe de manobra, alén das variacións que, paseniño pero continuamente, se van producindo nos niveis de coñecemento, uso e actitudes lingüísticas. Coa experiencia de traballar en estudos destas características desde hai xa demasiados anos, poucos 
engadidos realmente orixinais vexo, máis alá dos aumentos do monolingüismo en galego e castelán, o esperable incremento da competencia lectora -e en menor medida escrita- en galego e a matización da mellora das actitudes lingüísticas. A potencia e robustez das ferramentas analíticas probablemente ensombrecen as investigacións realizadas nos últimos tempos e tamén o feito de que xa non son politicamente tan rendibles.

Cómpre lembrar que o primeiro Mapa Sociolingüístico de Galicia se realizou baixo os auspicios do Partido Popular no poder, nunha época en que esta investigación probablemente serviu para o contrario, ou cando menos para algo moi distinto, do que en principio algúns vaticinaban. Non era infrecuente a comezos dos noventa escoitar a opinión de que o Mapa Sociolingüístico que preparaba a Real Academia Galega pretendía dar soporte científico á visión «bilingüista» proposta e sustentada daquela pola Xunta de Galicia. A Academia, pensaban algúns, como instrumento do poder "popular» só lle daría argumentos de carácter técnico ao goberno para seguir coa súa política de «bilingüismo harmónico» -e aquí incluiría un sector do socialismo galego, que, e nisto discrepo con Anxo, non corresponde só ao "período vazquista» senón a unha corrente dentro do PSdeG aínda vixente. Naturalmente, a realidade encargouse de quitarlles a razón a aqueles agoireiros e, unha vez publicado o Mapa, non foi estraño ver na prensa galega de tendencia nacionalista titulares como que «esta pode ser a xeración que perda o galego", mentres os medios oficiais en boa medida calaban.

As investigacións posteriores ratificaron de forma substancial a imaxe social da lingua galega trazada polo Mapa Sociolingüistico de Galicia e, en termos discursivos, serviron sobre todo para acentuar o dramatismo dalgunhas análises. $\mathrm{O}$ seu impacto viuse tamén algo ensombrecido pola recente ausencia de interese por facer culpable da situación ao PP, tras a chegada ao poder do goberno bipartito PSOE-BNG no ano 2005. Canto máis tempo pasa, menos poden argüír socialistas e nacionalistas que a culpa da situación é do goberno anterior, e máis poden temer ser culpados do que durante case tres décadas se tiña acusado aos conservadores ${ }^{1}$.

\footnotetext{
${ }^{1}$ Será interesante ver o rumbo que os condicionamentos e presións políticas máis recentes exercen sobre os inquéritos e estudos sociolingüísticos galegos que saian a partir da segunda metade de 2009, unha vez que o Partido Popular volve gobernar con maioría absoluta, contando paradoxalmente con Anxo Loren-
} 
Se a orixinalidade da análise proposta non procede de datos empíricos posteriores ao Mapa Sociolingüistico de Galicia, onde máis podería procurarse? Eu vexo dúas alternativas principais: por unha banda, na aplicación á realidade galega de marcos teóricos ata o de agora non utilizados, e por outra, na incorporación de perspectivas interpretativas e disciplinas diferentes das empregadas nas últimas décadas.

De maneira preliminar, creo que un deses puntos de vista estaría na Sociolingüística aplicada. É dicir, a posta en marcha de investigacións que proben a eficacia das medidas planificadoras, que pouco ou nada se teñen ensaiado en Galicia nas últimas décadas. O elo da avaliación, fundamental en planificación lingüística para comprobar a eficacia das medidas deseñadas, segue en boa medida ausente, con frecuencia baixo a escusa de que é economicamente custoso. Porén, nesta altura é case imprescindible para comprobar se estamos a actuar na dirección correcta, ou se debemos reenfocar as nosas actuacións, e nese caso cara a onde debemos dirixirnos.

Por poñermos exemplos de iniciativas posibles, poderiamos, ademais de investigar a eficacia dunha campaña de dinamización nun concello, universidade ou empresa galega, estudar cal é o motivo que frea ou anima un adolescente a falar galego, facendo un seguimento de casos concretos.

Outro aspecto importante, ao meu ver, é a reforma do discurso lingüístico e a súa diseminación social -que Anxo suxeriu na sección correspondente ás ideoloxías lingüísticas. Creo que esta reforma do(s) discurso(s) lingüístico(s) podería contribuír á mellora do tamén referido prestixio social da lingua galega, aínda que por si só non garante tal. Non estou certo de ata que punto iso é posible e tería que pensar máis devagar cal(es) sería(n) a(s) mellor(es) alternativa(s). Pero semella evidente que debemos desfacer e superar a bipolaridade entre, por unha banda, o discurso do «bilingüismo harmónico» e mais o rexeitamento á suposta «imposición» do galego, e por outra, os patrióticos chamados á «normalización» do galego -a saber, a recuperación da pretendida normalidade que na Idade

zo como novo secretario xeral de Política Lingüística. Nunca ata o de agora o goberno galego contara cun técnico na materia tan cualificado e cun currículo tan acaído para desenvolver ese importante labor. Escribindo esta nota engadida no comezo do estío de 2009, espero, polo ben de Galicia, que a incuestionable competencia e cualificación de Anxo Lorenzo contribúan a contrapesar a ruín e inxusta estratexia deseñada polo Partido Popular para frear a recuperación social da lingua propia de Galicia. 
Media supuxo a ecuación un país=un idioma. Creo que moitas vontades tentan hogano ver alén deste comportamento social bipolar e estancado. Con todo, para a consecución de tal fin é necesaria a superación dos bloqueos sociopolíticos varios establecidos desde diferentes bandas. Non é tarefa de todo doada, porque no proceso topamos con dinámicas antigas e estratexias que en certo sentido configuraron a identidade dos grupos políticos galegos. Para sermos máis concretos, por unha banda, o Partido Popular leva máis dun lustro inmerso no acoso e derribo dos «inimigos da unidade de España», grupo en que -agora como no franquismo- supostamente estamos os que propoñemos un espazo e unha vida digna para o galego e os seus falantes; entrementres, o Partido Socialista semella ter na súa cerna dislocada estilo tea de Penélope, na que as propostas galeguizadoras que uns tecen con agarimo durante o día outros as destecen por temor ou indecisión na noite.

Por outra banda, temos as dificultades derivadas dun nacionalismo político galego que, vendo freada a súa expansión social na última década, se atrincheira en axiomas sociopolíticos antigos arredor da idea de "normalización», sen gran frescura analítica e de actuación social. En todo caso, non sería xusto culpar o nacionalismo por seguir estancado neste marco interpretativo, dada a abafante presión en contrario que soporta, pero si sería bo alentar os principais animadores da promoción social do galego a procuraren novos argumentos e novas ideas coas que rexenerar discursivamente Galicia.

Aquí estamos a suxerir o discurso do multilingüismo, como unha posible maneira de seguir camiñando, e se cadra tamén de desfacer este círculo vicioso. Pero, en que consistiría este discurso do multi ou plurilingüismo? De que maneira podería ser útil para construír un discurso sociolingüístico eficaz? Como facer del algo máis que un discurso trendy?

Unha pregunta importante neste debate sería: que Galicia queremos lingüisticamente para o futuro? Procuramos simplemente garantir competencia oral e escrita en galego, ou queremos tamén que o idioma que se escoite maioritariamente no país, tanto nos espazos públicos como nos privados, sexa o galego? $\mathrm{Ou}$ simplemente deixar que cadaquén se exprese na lingua que queira? Neste último caso, que significa expresarse na lingua que un queira? Trátase acaso dunha decisión e vontade puramente individual? Podemos imaxinar e aceptar unha Galicia sen a lingua galega? Ningunha destas preguntas é retórica, mais con frecuencia 
non nos atrevemos a formulalas e, moito menos, a respondelas. Sen uns acordos mínimos semella difícil realizar unha planificación lingüística cunhas razoables garantías de éxito. Espero que, avanzada xa a primeira década do século XXI, poidamos chegar ao acordo de querer unha lingua galega como elemento de comunicación habitual e de cohesión da nosa sociedade, sen por iso impedir ou ignorar a existencia doutras linguas, que no contexto actual quere dicir o castelán.

Un problema neste sentido é a concepción, por parte dalgúns sociolingüistas, de que en Galicia non existen linguas como elementos discretos -en particular o galego-, senón simplemente un continuo lingüístico entre o galego e o castelán, no que a promoción do galego é un proceso ideolóxico sen base empírica. Trátase dunha estratexia baseada nun «solopsismo deconstrutivista», no que curiosamente se pon en dúbida só a existencia do galego, mais non a do castelán, o portugués ou outras linguas. Naturalmente, desde este punto de vista, resulta moi difícil, por non dicir imposible, calquera proceso de planificación lingüística. Coido que este "deconstrutivismo nihilista», tan común no contexto norteamericano, sobre todo entre certos académicos aparentemente progresistas e inscritos nunha posmodernidade aínda en voga, debe ser analizado desde unha perspectiva pragmática, considerando a súa viabilidade en contextos de planificación lingüística aos que a situación galega fornece un exemplo inmellorable para testar a súa adecuación.

Outra cuestión que suxire Anxo Lorenzo, e que considero moi pertinente, é se a dinamización do galego puido ser diferente e máis eficaz a partir da chegada da democracia a Galicia. Concordo con Anxo en que a actitude existente naquela altura era demasiado desfavorable ao galego para conseguirmos milagres. Ademais, as posturas maximalistas defendidas desde os sectores máis radicais do nacionalismo galego, que rexeitaban as opcións chamadas «bilingüistas» como forma de avanzar na recuperación social do galego, sen dúbida impediron o desbloqueo dos prexuízos lingüísticos e eivaron o avance da presenza social do galego, en particular no sistema educativo. De feito, a palabra «bilingüismo» foi tabú en Galicia e, sorprendentemente, símbolo de debilidade ou mesmo de deslealdade ao galego. E perdéronse, probablemente, dúas décadas nesta dinámica, que quizais aínda latexa detrás dalgunhas posturas na actualidade.

Unha cuestión máis que considerar é o equilibrio entre dominios sociais para conseguir unha planificación lingüística efectiva. Mediada a década dos setenta, 
moitos pensaban que a simple introdución do galego no ensino supoñería de seu a consecuente recuperación do galego. Como resultado daquela visión inxenua xurdiu a idea de que a clave estaba non no ensino «do» galego senón «en» galego. Porén, a relativa introdución desa práctica -imperfecta, desigual e inconsecuente, é certo- non conseguiu reverter a situación. Coido que o enfoque era tamén errado: como afirma Fishman con total rotundidade en Reversing Language Shift, "a escola soa non pode facelo». Na década dos noventa comeza a estenderse a necesidade e importancia de "vender en galego», como dicía a nosa publicación en 1996, e de darlle cando menos tanta importancia á difusión do galego no ámbito socioeconómico. En todo caso, eu creo que só se pode entender o proceso de recuperación social do idioma nun contexto de actuación global e desde un punto de vista holístico no que todas as actuacións están coordinadas e lle envían unha mensaxe clara e coherente á sociedade ${ }^{2}$.

Quixera agora suxerir, sequera brevemente, dous problemas relacionados coa psicoloxía social que están a frear o avance e o progreso social da lingua galega. Se ben a situación, como comentou Anxo, non é hoxe tan grave como no comezo do período democrático, cando os moito máis virulentos prexuízos lingüísticos pexaban o progreso do idioma de Galicia, aínda existen diversos factores contrarios, entre os que eu quixera destacar dous potentes elementos simbólicos de carácter psicolóxico presentes na sociedade galega: o "crítico interno» e o «autosabotador».

Estes dous conceptos teñen unha existencia longamente documentada na psicoloxía individual e mais na psicoterapia (Masters, 2007). O «crítico interno» -en inglés «inner critic»- é ese alter ego destrutivo que sistematicamente practica unha crítica continua, ás veces feroz, sobre si mesmo, non ten compaixón polas dificultades propias e, pase o que pase, dirixe a súa enerxía a culparse a si mesmo das dificultades, xustificándoas e desbotando a posibilidade de superalas.

\footnotetext{
${ }^{2}$ Con todo, quixera tamén dicir alto e claro que non é posible a recuperación social do galego, nin sequera o seu mantemento como lingua viva, se o poder político galego -o derivado dos comicios autonómicos de 2009- turra en rebaixar a presenza do galego no sistema educativo, elo non único mais si fundamental e inescusable na recuperación ou consecución do prestixio sociolingüístico que o galego precisa. Os cuestionamentos do carácter holístico e integral da promoción do galego só van redundar na súa perda de eficacia e no fracaso da dinamización da lingua propia de Galicia, que espero que non sexan obxectivos, sequera indirectos ou inconscientes, do goberno galego formado na primavera de 2009.
} 
O «sabotador»-tomado do francés «saboteur», de onde pasou ao inglés- é unha dimensión complementaria da anterior, outro alter ego que impide cambios xa en marcha, inminentes ou, en todo caso, claramente factibles, e que lles serve como claro freo ás esperanzas de cambio ou mesmo ás mudanzas que de facto se están a producir noutros niveis da vida do individuo.

A partir destes conceptos, pensados en principio para o individuo, propoño eu realizar unha extensión ao ámbito social, onde poden sernos útiles para analizar doutro xeito e con máis eficacia ese sentimento tradicionalmente coñecido entre nós como «autoodio»-concepto necesitado dunha profunda revisión- e así contribuír á reflexión sobre algúns procesos e fenómenos sociais que están a acontecer na Galicia contemporánea.

A crítica interna nunca é mala cando se concibe como sa autocrítica que busca liberar as accións dos posibles excesos do ego, sexa este individual ou social; mais cando se practica de forma sistemática e sen mesura converte ese san «crítico interno» en destrutivo "criticón», que nada positivo ve nas accións propias e que sempre está orientando as súas análises e opinións en termos negativos e esterilmente inmobilistas. Esa figura, en parte simbólica, en parte real, ás veces visible, ás veces agachada, está presente non só en cada individuo senón tamén en todo corpo social, e a sociedade galega non é unha excepción. As súas manifestacións son diversas, mais eu destacaría unha: o sentimento de inferioridade e de incapacidade para o cambio. A inferioridade séntese de diversas maneiras: por unha banda fronte a sociedades «maioritarias», dominantes ou principais -«mainstream» en inglés-; no caso galego, a española e a portuguesa; e por outra, sociedades de status homologable, que se perciben como superiores ou máis capacitadas para o cambio, e neste sentido a referencia principal é a sociedade catalá, pero tamén a vasca e mesmo outras culturas «minorizadas», que aínda tendo na maior parte dos casos unha lingua en situación de minoría máis intensa se perciben como máis sólidas e aceptadas. Outra dimensión deste fenómeno, sen dúbida conectada coa anterior, é a sensación de incapacidade para o cambio, a imposibilidade de que a partir da actual situación de «minorización» lingüística poidamos aspirar a outra diferente: como sempre fomos febles e derrotados en todas as nosas aspiracións e arelas, non podemos soñar con algo diferente, e inescusablemente debemos abrazar unha nai ou pai salvadores: no noso caso, España ou Portugal, en quen non vemos derrotas e só per- 
cibimos éxitos en que reflectirnos, como se dun espello se tratase; espello que en realidade é máis un espellismo ou "miraxe», pero que serve para aliviar o noso sentimento de frustración, inferioridade e desamparo.

$\mathrm{O}$ «crítico interno» sociolingüístico galego pode tomar formas moi diversas e adoptar xustificacións, escusas e estratexias de resistencia -ás veces numantinaben variadas, que van desde preparar informes -dramáticos- sobre a lingua galega, ata vaticinar que o idioma de Galicia se perderá a este ritmo en tres ou catro xeracións, ou mesmo que esta pode ser a xeración que perda o galego, como tantos estudos e titulares dos medios de comunicación argüíron nas últimas décadas. Teñen que ver coa experiencia colectiva e a memoria social e constitúen a ferida social, o estigma sociolingüístico recoñecible, sequera no nivel inconsciente: non somos suficientes, somos débiles e fáltanos valor. Así, os galegofalantes, os dous terzos -case o 67\%, segundo o Mapa Sociolingüístico de Galicia de 1995 - son menos importantes que o $50 \%$ que fala catalán ou o $25 \%$ que sabe falar éuscaro. E, de sermos preguntados ao respecto, xustificámonos coa escusa de que os nosos non son auténticos falantes de galego porque cambian facilmente ao español ou mesmo porque o seu galego non é suficientemente puro, e incluso oímos dicir que o seu non é realmente galego, senón algunha desas variedades híbridas, cuestión esta que xa mencionei anteriormente. Deste xeito abrimos a porta a dous fenómenos distintos pero procedentes da mesma falta de autoestima colectiva: a substitución do galego polo español e a purificación do galego a través do noso particular «primo Zumosol»: o portugués. Ese mesmo "crítico interno" dinos que non podemos cambiar a situación actual e que sempre que tentamos defendernos fomos derrotados -os Irmandiños, os mártires de Carral ou mesmo o mítico e probablemente imaxinario Monte Medulio, sempre presentes no noso subconsciente colectivo.

$\mathrm{O}$ «crítico interno», en definitiva, é un elemento psicolóxico moi persistente, sobre todo en individuos e sociedades con feridas antigas e profundas, que reconverte adoito elementos positivos en negativos cunha gran facilidade, que dubida das súas potencialidades con argumentos construídos cunha aparente gran coherencia e que eficazmente desmonta os intentos realizados desde fóra dese corpo -individual ou social- para reverter a situación. Con frecuencia tamén, cando a situación ou ben foi transmitida por persoas ou xeracións precedentes, ou ben a ferida foi experimentada desde momentos moi antigos da 
vida -do individuo ou da sociedade-, van aparecer a convicción -consciente ou inconsciente- de que todo está perdido ou de que calquera cambio é imposible, e neste aspecto enlazan os roles do "crítico interno» e do "autosabotador».

Aínda que o efecto do noso «inner critic» é moi forte, cando este, por algunha razón, consegue neutralizarse o reforzamento da autoestima -a social galega, no noso caso- produce resultados inesperados. Pensemos na campaña "Vivamos como galegos" da empresa distribuidora Gadis ou, noutro nivel, no éxito comercial de R. Estas iniciativas publicitarias e comerciais, que conseguiron o seu éxito en parte grazas ao uso do galego, son algúns dos exemplos contemporáneos máis salientables deste fenómeno. Nese mesmo nivel é onde se entenden os resultados de estudos sobre actitudes lingüísticas como os reflectidos en Vender en galego, que Ramallo e Rei-Doval (1997) realizamos para o Consello da Cultura en 1995-1996, ou a visión -moderadamente- optimista do volume Actitudes lingüísticas en Galicia, de 1996. Cando lle damos aos galegos e galegas a oportunidade de creren en si mesmos, a autoestima aboia, pero cando aplicamos toda a nosa «crítica interior», o noso «lado escuro» emerxe no seu estado máis puro.

O outro elemento do que cómpre falar é a figura do «sabotador», que na nosa sociedade, de xeito consciente ou semiconsciente, tenta impedir que certos cambios cheguen a producirse, por temor á aparición dunha sociedade diferente, máis incerta e menos controlable. Nestes termos deben entenderse os intentos, desde determinados sectores da sociedade galega, de impedir que avance o proceso de difusión social do galego. Naturalmente, a actuación destes grupos sociais está motivada, desde outra óptica, polos intereses e as estratexias políticas dun nacionalismo español que non quere ver minguado o seu poder, dominación e capacidade de influencia en Galicia. Mais os executores desas políticas forman parte, na maioría dos casos, do tecido social galego. Estoume a referir, naturalmente, a grupos de presión como a desaparecida Asociación Gallega para la Libertad de Idioma (AGLI) ou a máis contemporánea Tan Gallego como el Gallego, recentemente disolvida en Galicia Bilingüe. Todas elas representan o que eu chamaría «Comité de Sabotaxe da Regaleguización»; forman parte da nosa estrutura social e son resultado das miserias e derrotas que pexaron o noso desenvolvemento colectivo. Así, opóñense aos cambios para recuperar a dignidade social do galego dos que eles mesmos son resultado como grupo. E, canto 
máis clara e decidida é esa vontade de cambio e recuperación da dignidade sociolingüística desde certos sectores, con máis forza se expresan e actúan os sabotadores, que condensan, axitan e lanzan como arma de combate a súa resistencia á regaleguización, utilizando como maquillaxe discursiva tópicos que apelen a algunha parte do "crítico interno» dos galegos, e que con frecuencia lles serven de lexitimación e escudo. Se este "crítico interno" non estivese tan desenvolvido pola falta de autoestima colectiva a sabotaxe non tería éxito, xa que non enraizaría no tecido social.

A sabotaxe fronte ao cambio que se intúe ou mesmo se percibe na sociedade -e no individuo- é o resultado da combinación de dous elementos: a rabia -normalmente contida, dado o rexeitamento que nas nosas culturas esperta este elemento cando é formulado en contextos formais- e o medo -ás veces, case pánico- ao cambio, que produce unha parálise ou inacción que, como un búmerang, ás veces se reconverte na referida resistencia, oposición activa e incesante, ao cambio. Unha das características máis rechamantes desta «autosabotaxe» é a inmensa cantidade de enerxía que se perde nela, e que, canalizada eficazmente, podería producir beneficios -sexan no nivel individual ou no social- simplemente inmensos. Se somos capaces de desfacer estes nós, pode producirse unha cantidade de enerxía tal que o progreso ou felicidade conseguida supere os máis optimistas vaticinios.

Fronte a esa realidade, os principais recursos consisten en facer visibles as inconsecuencias e a inxustiza das prácticas sabotadoras, así como o prexuízo que para o progreso, o cambio e a procura do benestar social supoñen estas, sen nunca negar o dereito a discrepar ou a diversidade cultural e social de Galicia. Mais iso non debería impedir a firmeza na procura da recuperación social do galego nin a posta en práctica de accións que conduzan cara a tal fin. A sabotaxe nunca pode ser contestada coa parálise ou renuncia a obxectivos lexítimos, senón cunha acción firme e serena na procura de cambios sociais que son xustos e necesarios. 


\section{BIBLIOGRAFÍA}

Fishman, J. A.: Reversing Language Shift, Multilingual Matters, Clevedon, 1991.

MASTERS, R. A.: Transformation through Intimacy, Techmenos Press, 2007.

Ramallo, F. e G. Rei-Doval: Vender en galego, Santiago de Compostela, Consello da Cultura Galega, 1997.

Seminario de Sociolingứstica da Real Academia Galega: Usos lingüisticos en Galicia, A Coruña, Real Academia Galega, 1995.

Seminario de Sociolingứstictica da Real Academia Galega: Actitudes lingüisticas en Galicia, A Coruña, Real Academia Galega, 1996. 